ATOMICS INTERNATIONAL

A Division of North American Aviation

Do not remove this sheet

\title{
UNCLASSFIED
}

Classification

NAA-SR-MEMOS are working papers and may be expanded, modified, or withdrawn at any time, and are intended for internal use only. Further dissemination is not permitted and distribution to abstracting agencies is not authorized.

Each person who receives this document must sign the cover sheet in the space below.

\begin{tabular}{|c|c|c|c|c|c|}
\hline Route to & Noted by & Date & Route to & Noted by & Date \\
\hline & & & & & \\
\hline & & & & & \\
\hline & & & & & \\
\hline & & & & & \\
\hline & & & & & \\
\hline & 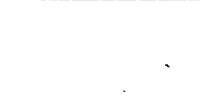 & & & & \\
\hline & & & & & \\
\hline & & & & & \\
\hline & & & & & \\
\hline
\end{tabular}




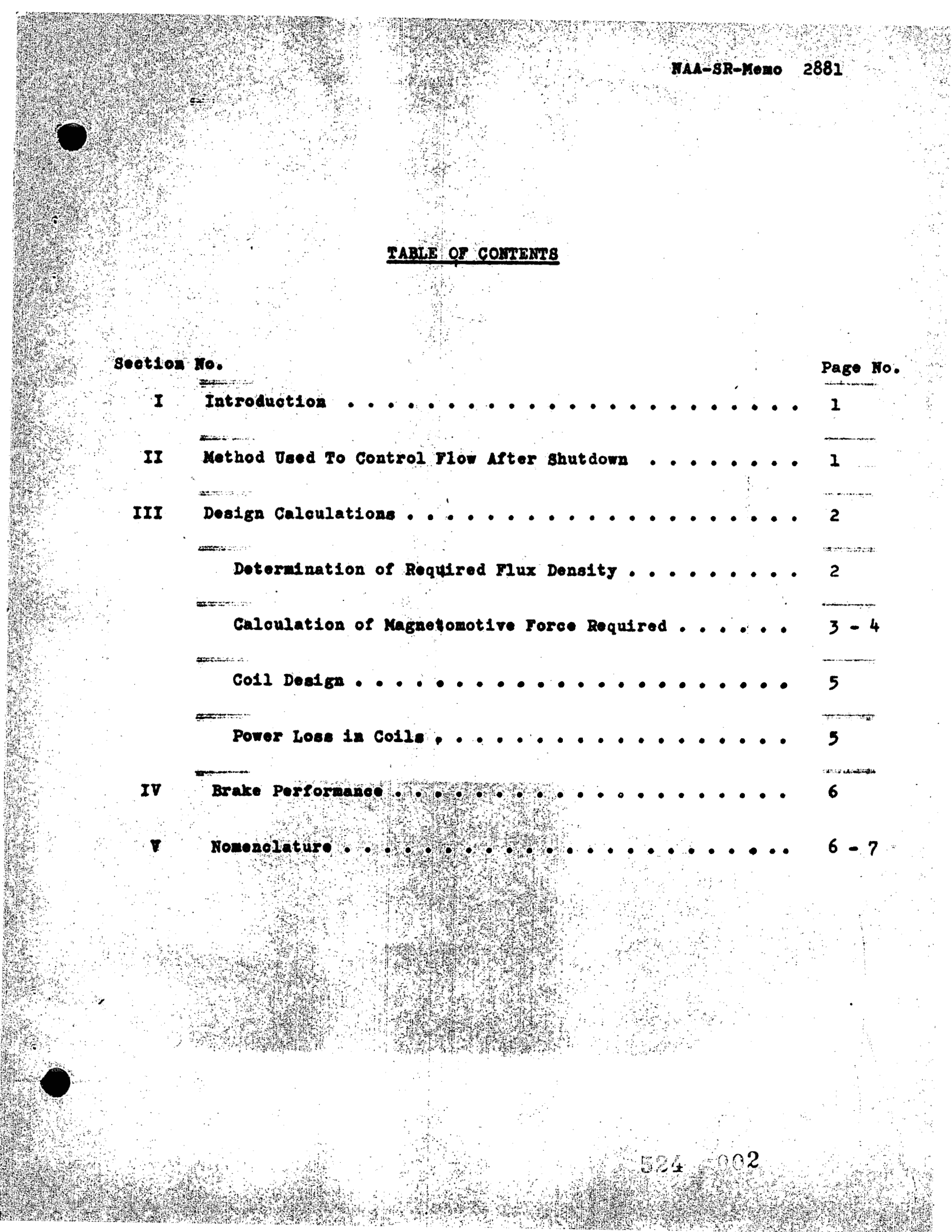


LIST OF ITGURES

P1gure Io.

Page No:

1 Eddy-Current Brake (ehowing crose section of braking section) 8

2 Cross seotion of Braklas section . . . . . . . . . 9

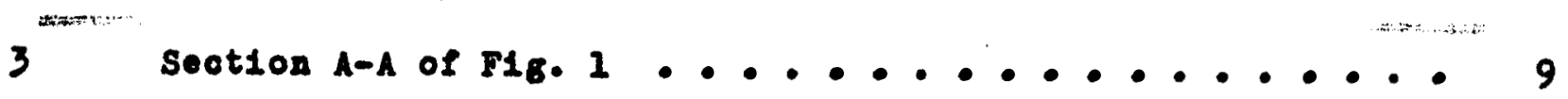

4 Side view of Eddy-Current Brake . . . . . . . ... 10

5 VIew of Ioke without Co1lo and Braking section . . . . . 11

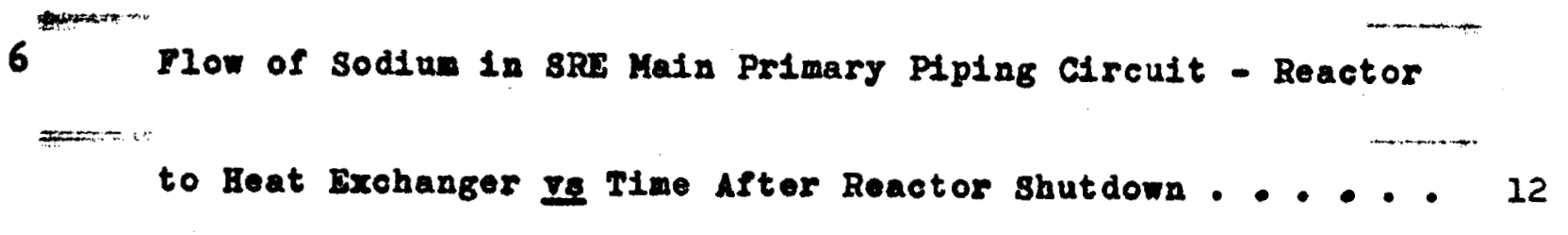

7 Temperature of Sodium at SRE Reaotor Outlet to Primary

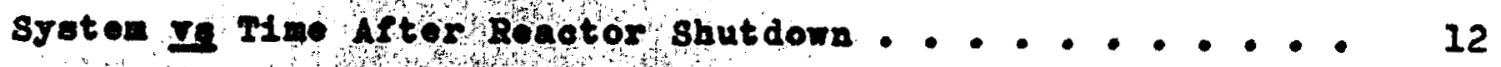




\section{DESIGN OF AN EDDY_CURRENT BRAKE FOR A SODIUM-COOLED NUCLEAR POWER REACTOR}

By

R. S. Baker

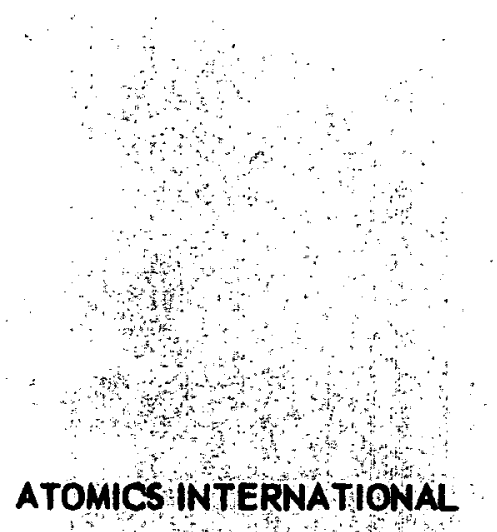

A Division of North Amoricon Aviation, Ine. 


\section{DESIGN OF AN EDDY-CURRENT BRAKE FOR A SODIUM-COOLED NUCLEAR POWER REACTOR}

\section{INTRODUCTION}

The sodium-cooled nuclear power reactor: known as the Sodium Reactor Experiment (SRE) is operated by Atomics International, a Division of North American Aviation, Inc., for the Atomic Energy Commission. The reactor is located in the Santa Susana Mountains near Los Angeles. The design features of this reactor have been outlined by Dr. S. Siegel. ${ }^{1}$

During the early operation of this reactor, it was determined that some form of sodium-flow throttling device was necessary to prevent excessive thermal stresses from occurring in the reactor core and sodium piping after a shutdown, or "scram."

When the reactor is shut down, the production of heat within the reactor becomes a small fraction of its former value. This small amount of heat (due to afterglow) that is still being produced is sufficient to cause circulation of sodium into and out of the reactor by thermal convection. The result ts that sodium, at a relatively low temperature, is brought into contact with piping which is still at a high temperature, thereby leading to excessive thermal stresses. These stresses can be minimized by controlling the sodium flow in proportion to the heat generation, resulting in constant temperature gradients.

\section{METHOD USED TO CONTROL FLOW AFTER SHUTDOWN}

For the purpose of throttling the odium now throughout the reactor piping to maintain a constant reactor temperature gradient for afterglow power condi tions, two eddy-current brakes were ln talled in the SRE. One lis used on the primary piping ystem, the other on the secondary system. Each is constructed as shown in Fig. 1 . 
Both brakes are controlled by thermocouples that measure sodium temperatures in primary and secondary systems.

Performance has been satisfactory. The braking pressures that have been obtained at different sodium flow rates agree with calculated figures.

\section{DESIGN CALCULATIONS}

Determination of Required Flux Density

To begin the design of the direct-current electromagnet which constitutes the brake, a basic configuration was assumed. This is shown in Fig. 1 .

Dimensions of the braking section and thermal barriers are shown in Fig. 2 . The symbols that appear in Fig. 2 represent quantities that will be used later in the design calculationa.

Figure 3 shows dimensions of the braking section and pole face in planes parallel to the flow direction.

Figure 4 is a side view of Fig. 1.

The calculation of magnet design to produce a given braking pressure is based on Rudenberg's equation for the eddy-current drag on a copper disk. ${ }^{2,3}$ Written in terms of the quantities used in designing the eddy-current brakes, this equation becomes:

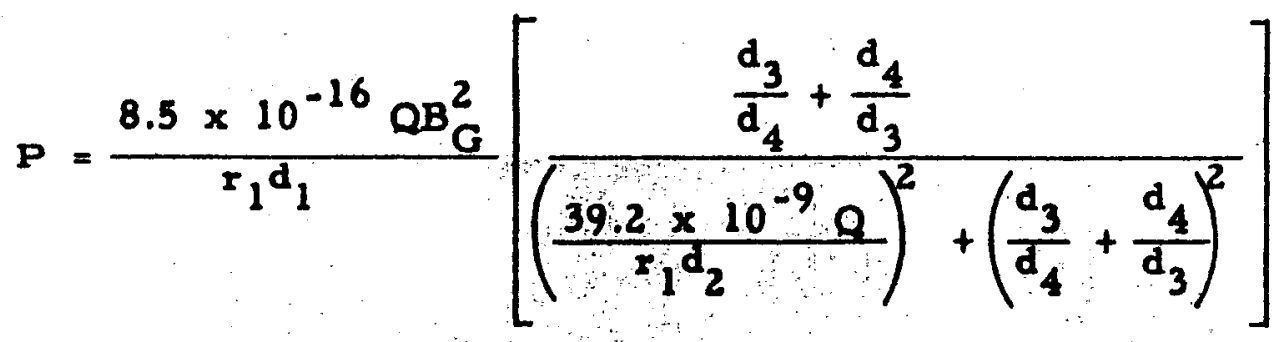

In test runs conducted at the $\mathbf{S R}$, it was determined that under acram conditions, the sodium flow rate in the main primary circuit, through the reactor, should drop to about 12 gallons perminute It was al so determined that the eddycurrent brake houldcause a dragging presure of 0.3 pound per square inch at thi flow rate. The fux deneity neceofery to produce this drag preseure was calculated from Eq. (1), for a codium temperature of $1000^{\circ} \mathrm{F}$. 
$\vec{P}=0.3$ pound per square inch

$d_{1}=2$ inches

$d_{2}=4$ inches

$d_{3}=7-3 / 4$ inches

$d_{4}=10$ inches ( This value was determined by adding an estimated amount of 2.25 inches for pole face chamfer to $d_{3}$ )

$Q=12$ gallons per minute

$r_{1}=10.5 \times 10^{-6} \mathrm{ohm}-$ inches

Solving for ${ }^{B}{ }_{G}$ :

$$
{ }^{B} G=35,800 \frac{\text { lines }}{\text { Bquare inch }}
$$

\section{Calculation of Magnetomotive Force Required}

The next step in the design was the calculation of the coil ampere-turns required to set up this flux density. Two colls were used, one on each side of the air-gap, and placed as close as possible to the gap. Each coil was proportioned to have the maximum ratio of inductance to resistance, as nearly as possible. This requires that each coil be square in cross section, with a mean diameter which is 3.02 times the length of one side. ${ }^{4,5}$ (See Fig. 1 and 4.) It was not possible to construct the magnet yoke to meet this requirement precisely, because of space limitations; however, the actual performance has not been measurably affected.

The effects of fringing and leakage were taken into account by empirical and analytical methods. 6,7 The first of these, the fringing effect, causes an increase in the magnetomotive force as denoted by the fringing factor $f_{1}$ in the equation:

$$
A T_{G}=0.313 B_{G} d_{2} F_{1}
$$

From p. 14 of Ref. 6, $f_{1}=1.5$. Thus:

$$
A T_{G}=0.313 \times 35,800 \times 4 \times 15=67,100 \text { ampere-turns. }
$$


The second effect, the leakage factor $f_{2}$, was used in calculating the magnet yoke dimension $d_{6}$ in the equation:

$$
\begin{gathered}
d_{4} x d_{6}=\frac{f_{2}{ }^{B} G_{G}^{A}}{B_{m}} \\
f_{2}=1+\frac{3.4 d_{2}\left(d_{4}+d_{6}\right)}{d_{4} d_{6}}\left[\frac{d_{8}}{d_{2}+d_{8}}+\frac{0.45 d_{4}}{d_{2}+0.67 d_{4}+2 d_{8}}\left(1+\frac{d_{2}+2 d_{8}}{d_{4}}\right)\right]
\end{gathered}
$$

The values of the quantities in the right-hand member of Eq. (4) are lioted below. It will be noted that a value of 10 inches was assumed for $d_{6}$, which resulted in a square cross section of the yoke. The procedure was to calculate $f_{2}$, then solve for $B_{m}$ in $E_{q}$. (3). If the value of $B_{m}$ thus determined had been greater than the saturation flux density of 115,000 lines per square inch, it would have been necessary to assume a larger value for $d_{6}$. As shown by the calculations that follow, the value of 10 inches is satiofactory.

$$
\begin{aligned}
& d_{2}=4 \text { inches } \\
& d_{4}=10 \text { inches } \\
& d_{6}=10 \text { inches } \\
& d_{8}=0.5 \text { inch }
\end{aligned}
$$

Then $f_{2}=2.86$, and upon substituting this value in Eq. (3) and solving for $B_{m}$, it was found that $B_{m}=102,000 \frac{\text { lines }}{\text { gquare inch }}$, which is a satisfactory operating flux density for the steel yoke. The reluctance drop in the steel from one side of the air-gap, through the yoke around to the other side, was found to be 8880 ampere-turns. ${ }^{8}$. This amount was added to the air-gap ampere-turns calculated in Eq. (2); to determine the wire size necessary for the coils. 


\section{Coil Design}

The next step in designing the brake was to assume a coil current (I) of 10 amperes, direct current. Then, under the assumption that the coil is square in cross section, $d_{4}=d_{5}=10$ inches.

The mean length of turn $d_{7}$ was calculated by the equation:

$$
\begin{aligned}
& d_{7}=2\left(d_{4}+d_{5}\right)+2\left(d_{6}+d_{5}\right)=2\left(d_{4}+2 d_{5}+d_{6}\right) \\
& d_{7}=80 \text { inches }
\end{aligned}
$$

The cross-section area of the coil conductor for a winding temperature of $60^{\circ} \mathrm{C}\left(140^{\circ} \mathrm{F}\right)$ was calculated from the equation:

$$
A=\frac{\mathrm{kd}_{7} \mathrm{NI}}{1.16 \mathrm{E}}
$$

where

$$
\begin{aligned}
& k=\frac{100}{98}+0.004(60-20)=\begin{array}{l}
1.18 \text { for copper of } 98 \text { per cent conductivity } \\
\text { at } 60^{\circ} \mathrm{C}
\end{array} \\
& \mathrm{NI}=\frac{67,100+8,880}{2}=37,990 \text { ampere-turns per coil } \\
& E=120 \text { volts } \\
& A=\frac{1.18 \times 8037,990}{1.16 \times 120}=25,200 \text { circular mils. }
\end{aligned}
$$

No. 6 AWG double glass insulated wire was used for winding the coils, each of which was wound with approximately 3400 turns. The cross section of each coil is approximately 10 inches by 10 inches; therefore, the initial choice of magnet dimensions was correct.

\section{Power Loss in Coils}

The resistance of each coil at the operating temperature was calculated from:

$$
r_{2}=\frac{k d_{7} N}{1.16 \mathrm{~A}}
$$


where

$$
\begin{aligned}
& \qquad \mathbf{r}_{2}=\frac{1.18 \times 80 \times 3,400}{1.16 \times 22,700}=12.2 \mathrm{ohms} \\
& \text { Power } 108 \mathrm{~s} \text { in each coil }=10 \times 120=1200 \text { watts. }
\end{aligned}
$$

\section{BRAKE PERFORMANCE}

The effects of the eddy-current brake on the primary system are shown in Fig. 6 and 7 . These curves illustrate the manner in which sodium flow in the primary system and sodium temperature at the reactor outlet vary with time for the condition where the brake is not energized, and the condition where the brake is energized, at the time of reactor shutdown.

\section{NOMENCLATURE}

$P=$ Dragging pressure (psi) in the sodium

$Q=$ Sodium flow through the braking section (gpm)

$d_{1}, d_{2}, d_{3}, d_{4}=$ Dimensions (inches) of braking section, shown in Fig. 1, 2, and 3 .

${ }^{B}{ }_{G}=$ Flux density in sodium (lines per square inch)

$r_{1}=$ Resistivity of sodium (ohm-inches)

$f_{1}=$ Fringing factor (dimensionless)

$f_{2}=$ Leakage factor (dimensionless)

$A T_{G}=$ Ampere-turne for the air-gap

$B_{m}=$ Flux density in steel yoke (lines per square inch)

$d_{5}=$ Coil dimensions (inches) shown in Fig. 1

$d_{6}=$ Yoke dimension (inches) shown in Fig. 1

$d_{7}=$ Mean length of coil turn (inches)

$a_{8}=$ Space between edge of coil and pole face (inches)

$A=$ Cross-section area of coil conductor (circular mils) 
NAA-SR-Meno 2881

$k=$ Ratio of the resistivity of the copper conductor used in the coil winding to that of standard annealed copper at $20^{\circ} \mathrm{C}$. For copper of $\mathrm{C}$ per cent conductivity at $T^{\circ}$ centigrade,

$$
k=\frac{100}{C}+0.004(T-20)
$$

$N=$ Number of turns per coll

$$
\begin{aligned}
& I=\text { Coil current (amperes) } \\
& \mathbf{E}=\text { Coil voltage }
\end{aligned}
$$

$$
\begin{aligned}
A W G & =\text { Abbreviation for American Wire Gage for nonferrous metals } \\
r_{2} & =\text { Resistance (ohms) of each coil at the operating temperature } \\
A_{G} & =\text { Area of pole face (square inches) } \\
A_{G} & =d_{4} \times d_{6}
\end{aligned}
$$

$-7-$

$$
\text { set } 01
$$




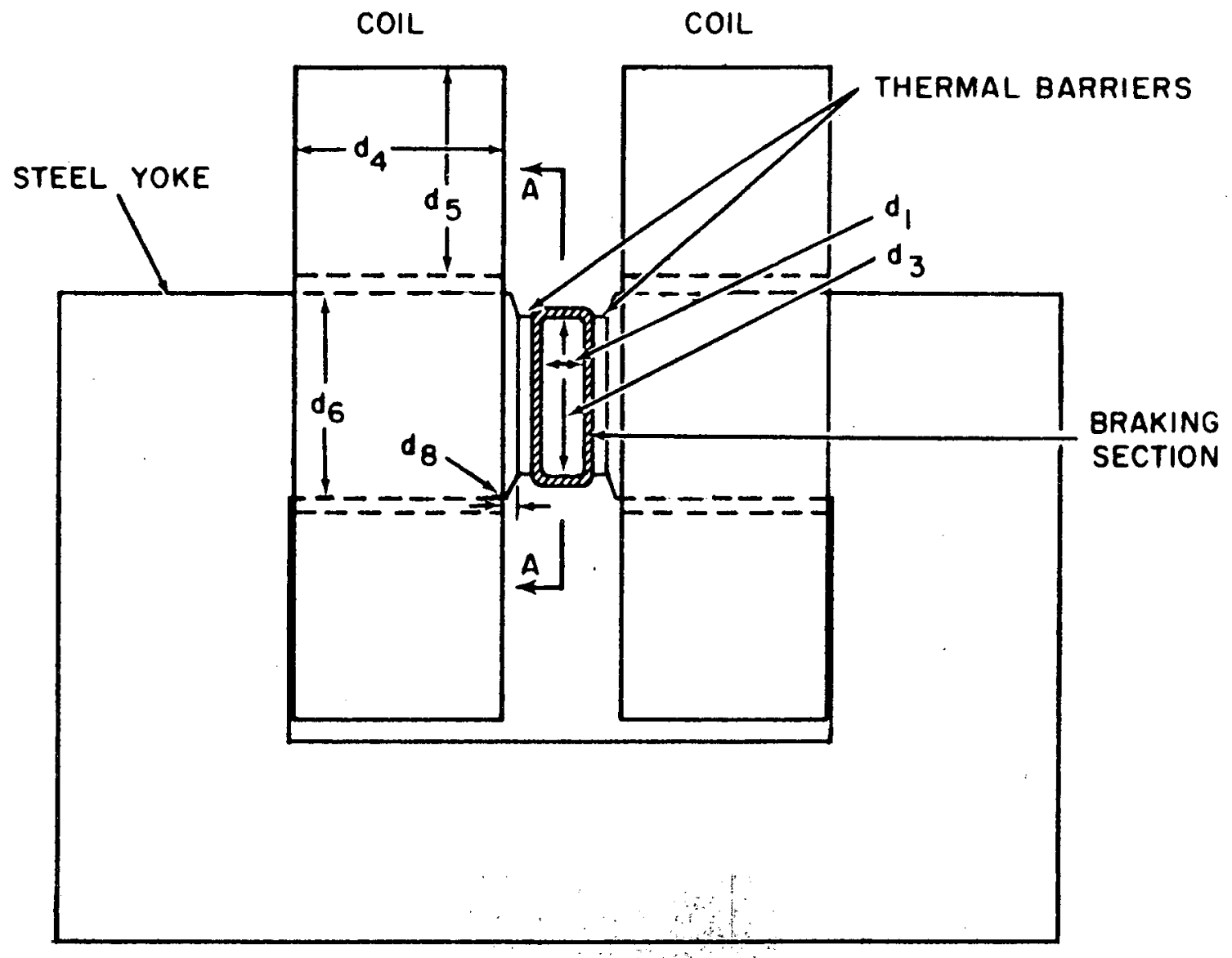

Fig. 1. Eddy-Current Brake (showing cross section of braking section)

$$
-8-
$$

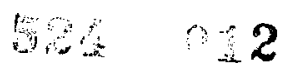





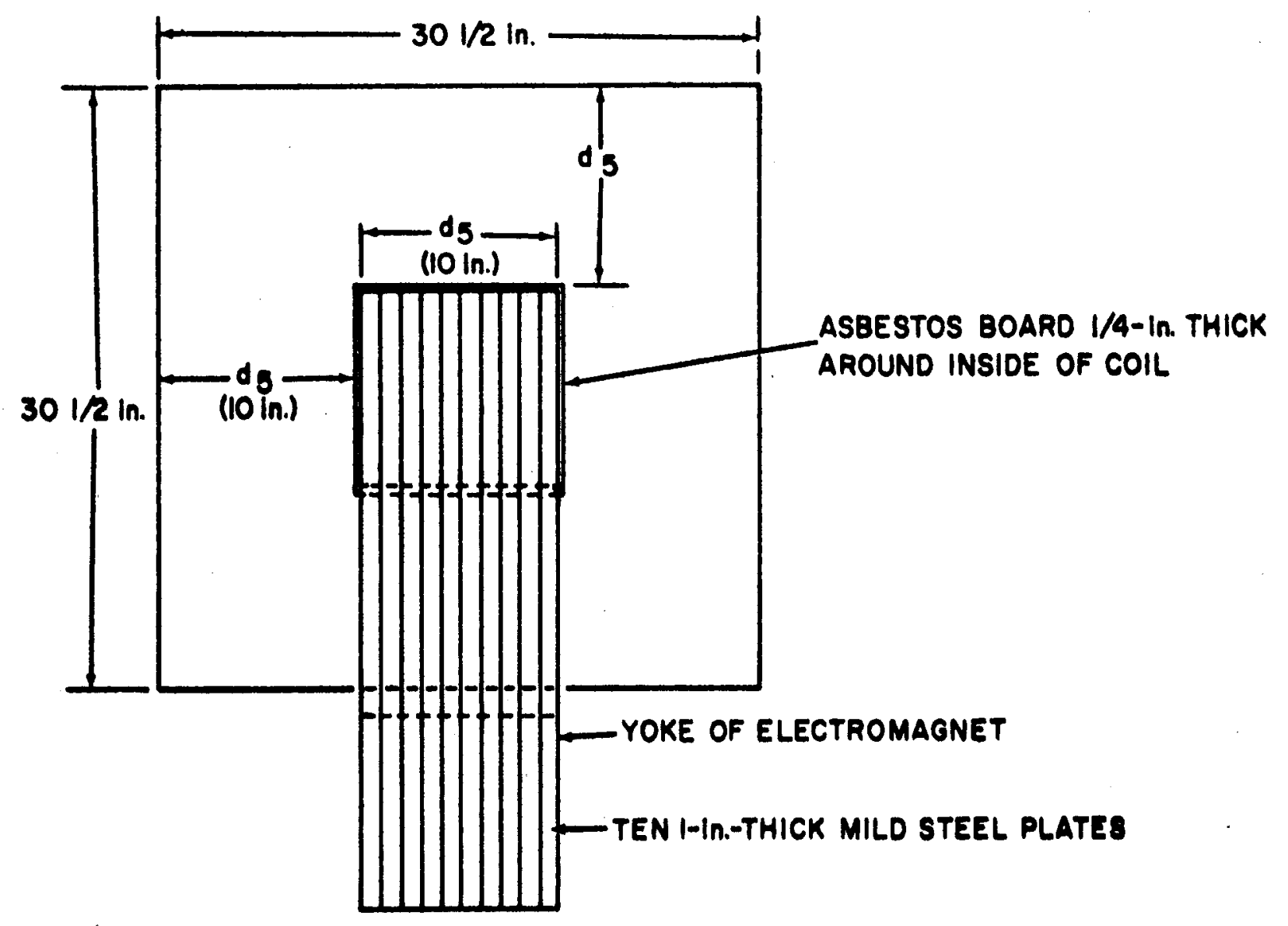

Fig. 4. side View of Eddy-Current Brake

$$
528 \text { nt }
$$




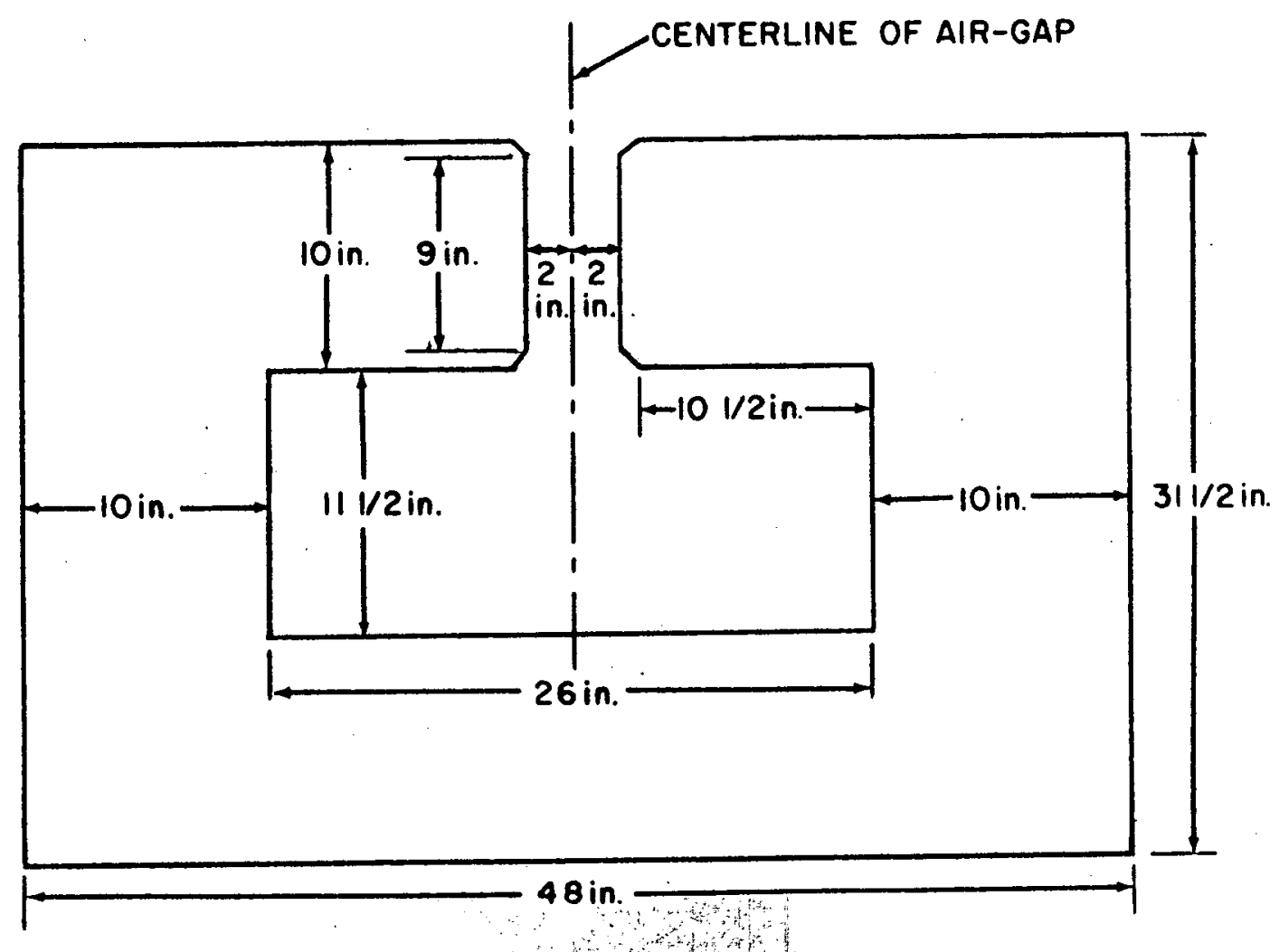

Fig. 5. View of Yoke Without Coile and Braking Section 


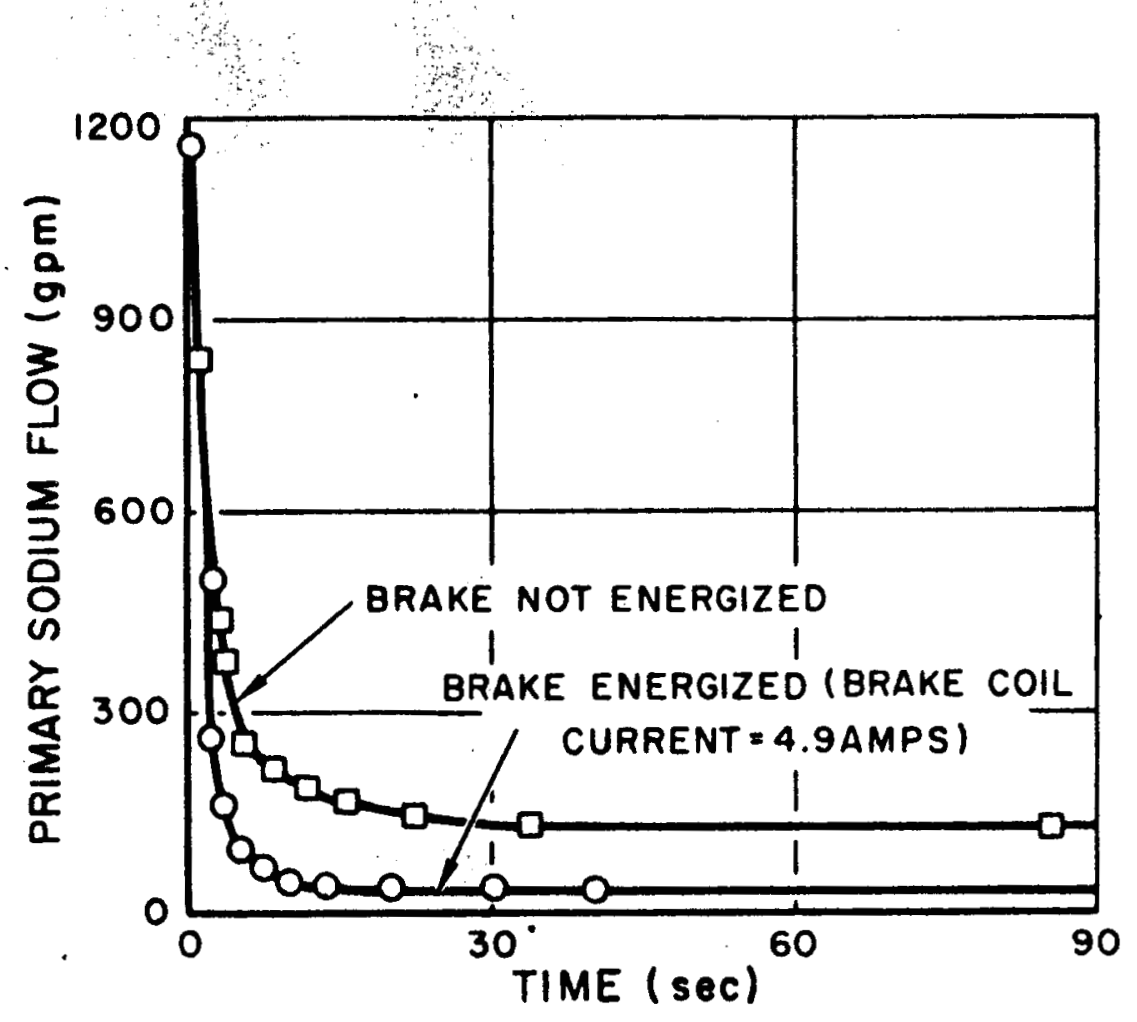

Fig. 6. Flow of Sodium in SRE Main Primary Piping Circuit - Reactor to Heat Exchanger va Time After Reactor Shutdown

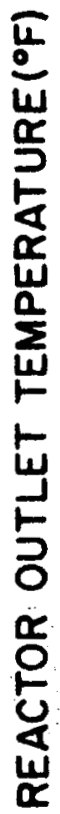

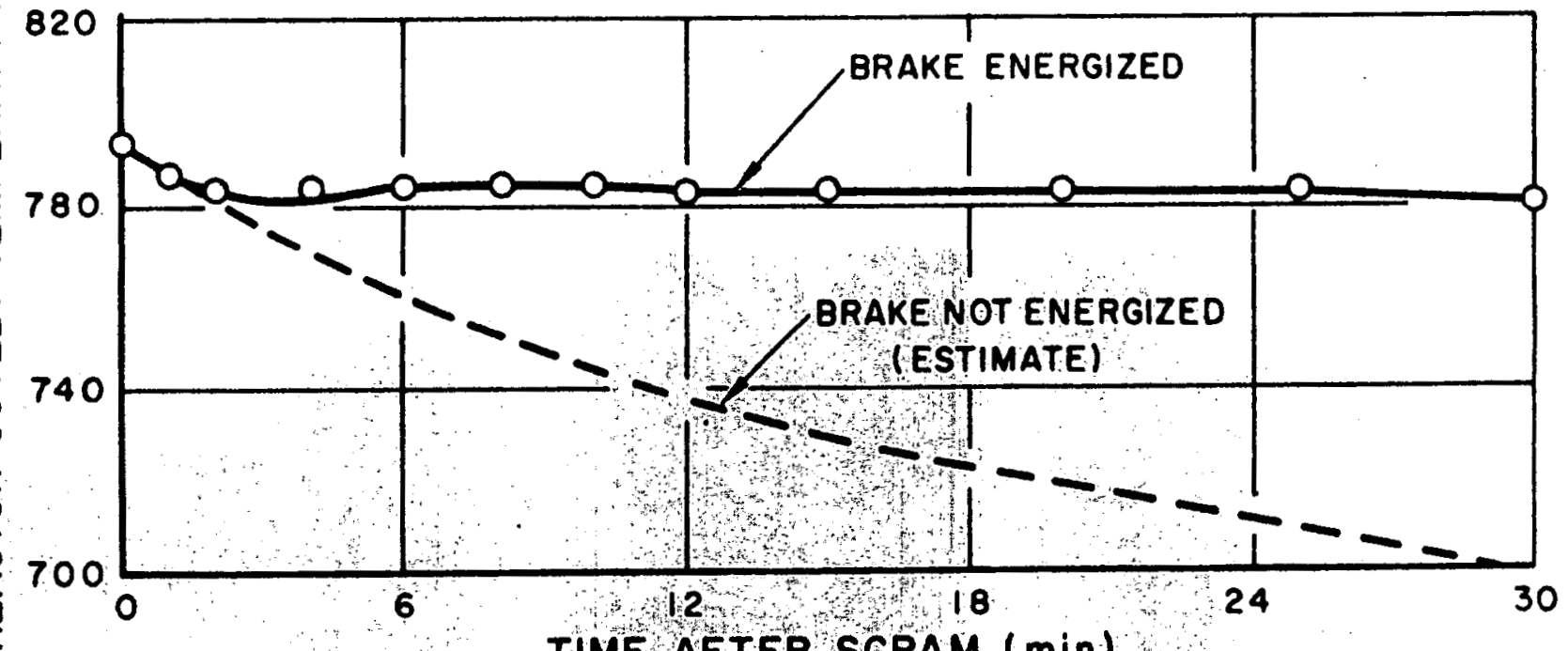

TIME AFTER SCRAM $(\mathrm{min})$

Fig. 7. Temperature of Sodium at SRE Reactor Outlet to Primary Syotem va Time After Reactor Shutdown 
11. S. Siegel, "The Sodium Graphite Reactor Electric Power Plant," Electrical Engineering, 76, No. 1, p. 60 (January, 1957).

2. R. Rudenberg, "Energie der Wirbelstrome in Elektrischen Bremsen und Dyriamomaschinen," Sammlung Elecktrotechnischer Vortrage (Stuttgart, Germany: Ferdinand Enke, 1907), X, p. 269.

3. R. S. Baker, "Calculation of Developed Pressure and Fluid Power in Linear Polyphase Induction Liquid Metal Pumps," Mine Safety Appliances Company Technical Report 48, March 24; 1956.

4. MIT Staff, Magnetic Circuits and Trangformers (John Wiley and Sons, Inc., 1943), footnote p. 76.

5. U. S. National Bureau of Standards Circular C74, p. 294, (Washington, D.C.: U. S. Government Printing Office).

6. Earl M. Underhill, Permanent Magnet Design (Pittsburgh, Pa.: Crucible Steel Company of America).

7. R. K. Tenzer, "Estimating Leakage Factors for Magnetic Circuits by a Simple Méthod, "Applied Magnetics 5 No. 2, Eq. 14 (Valparaiso, Ind.: Indiana Steel Products Co., April - June 1957).

8. Electrical Steel Sheets, Engineering Manual (4th Ed.; Pittsburgh, Pa.: U. 5. Steel Corp. I, p. 258.

9. Pender and Del Mar, Electrical Engineerg' Handbook (4th Ed.; John Wiley and Sons, Inc., 1949), section 6-31.

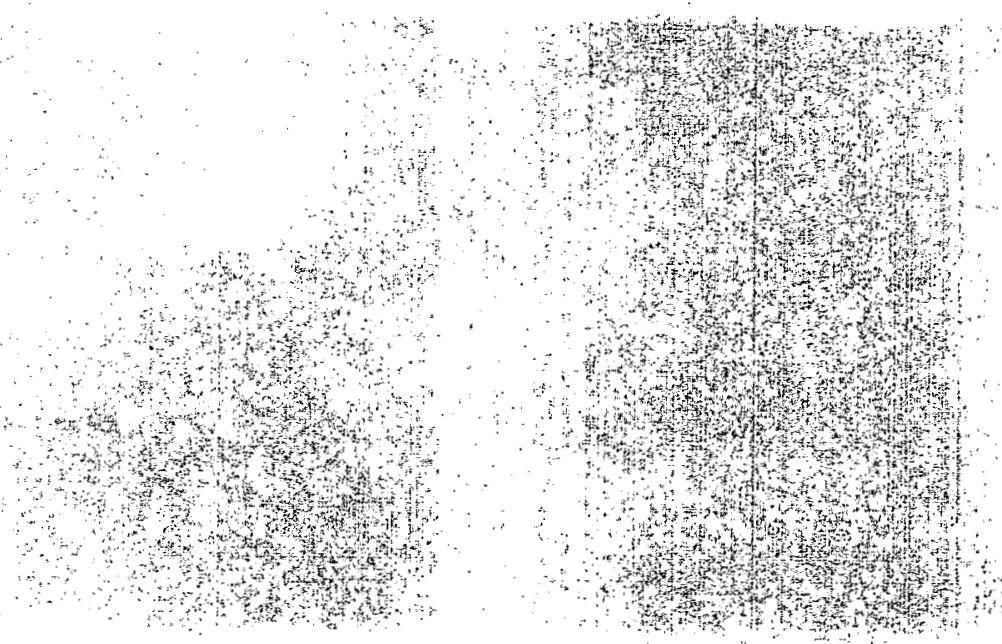

